\title{
Treatment of multiple esophageal diverticula by peroral endoscopic myotomy
}

A 55-year-old man with persistent dysphagia and chest pain for 5 years was referred to our medical team. Gastroscopy (Olympus, Tokyo, Japan) revealed two distinct diverticula: one mid-esophageal diverticulum located $33 \mathrm{~cm}$ from the incisors and another "kissing" epiphrenic diverticula $43 \mathrm{~cm}$ from the incisors ( $\triangleright$ Fig. 1 , preoperation). Barium swallow showed the size of the esophageal diverticula to be $4 \mathrm{~mm}, 19 \mathrm{~mm}$ and $22 \mathrm{~mm}$, respectively ( $\$$ Fig. 2 , preoperation). Esophageal manometry showed no findings of a primary motility disorder ( Fig.3).

The patient asked for minimally invasive therapy, so we used peroral endoscopic myotomy (POEM) ( Video 1). A 2-cm oblique mucosal incision was made between the "kissing" diverticula, at $3-5 \mathrm{~cm}$ above the diverticula, using a triangle-tip knife positioned at the tunnel entry. Another incision was made on the same side $3-5 \mathrm{~cm}$ above the single diverticulum, which was $33 \mathrm{~cm}$ from the incisors. For both diverticula, a submucosal longitudinal tunnel was made on each side of the septum and ended $1-2 \mathrm{~cm}$ distal to the bottom of the diverticulum. Circular muscle, longitudinal muscle, and base muscle between the esophageal lumen and diverticulum were dissected using the triangle-tip knife ( $\triangleright$ Fig.4, $\triangleright$ Fig.5). Finally, the mucosal incisions were closed with hemostatic clips.

The patient took semifluid food the following day, and was discharged from hospital on postoperative day 7 with symptoms completely resolved. A barium swallow test 1 week later showed a dramatically flatter diverticula bottom ( Fig. 2, postoperation). The 1-month follow-up gastroscopy showed increased esophageal lumen ( $\mathbf{F i g . 1}$, postoperation), and the patient had gained $3 \mathrm{~kg}$ in weight.

The first application of POEM was reported in 2010 [1]. Since then, POEM has been applied to gastroparesis and esophageal diverticulum [2-3]. In the present
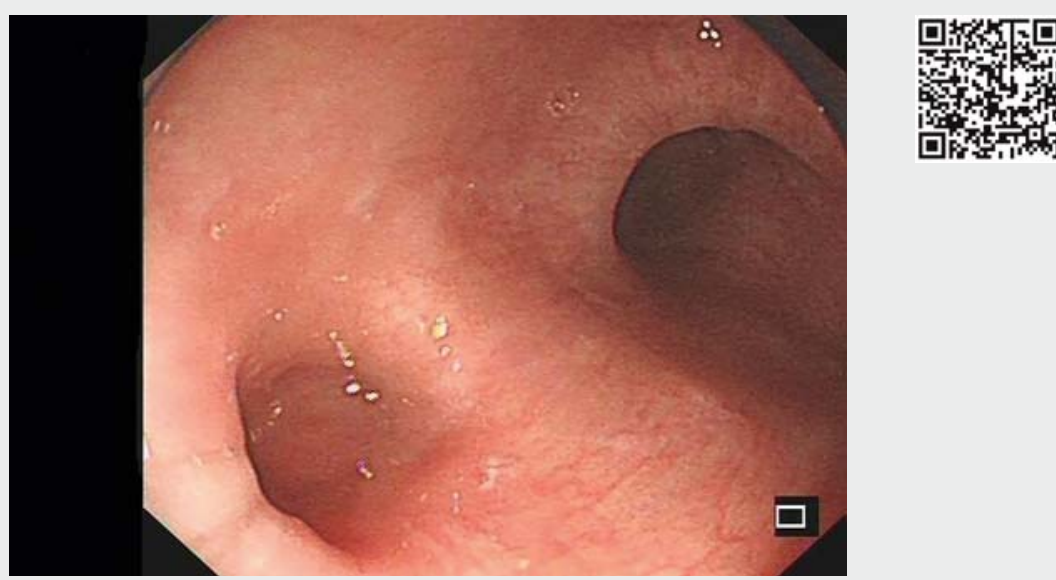

Video 1 Gastroscopy showed multiple esophageal diverticula, which were treated successfully by peroral endoscopic myotomy.

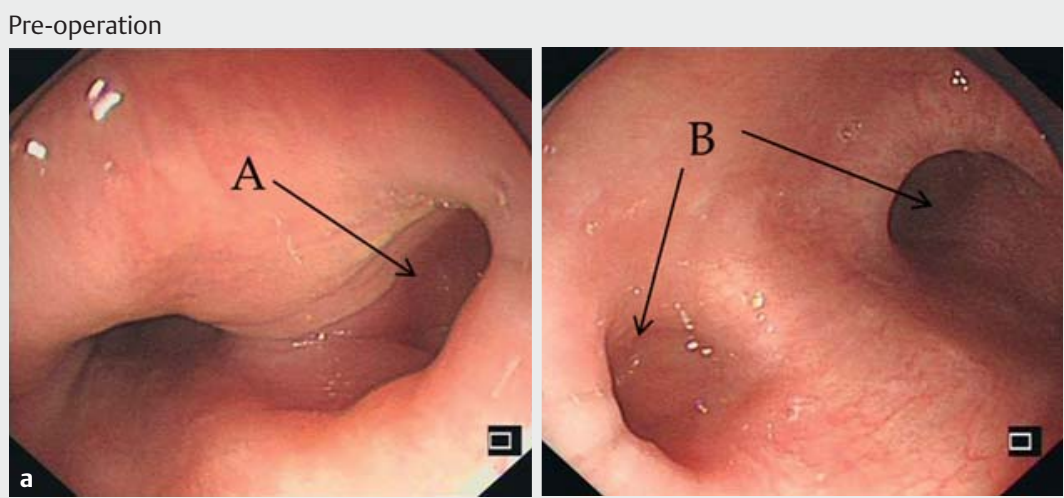

Post-operation
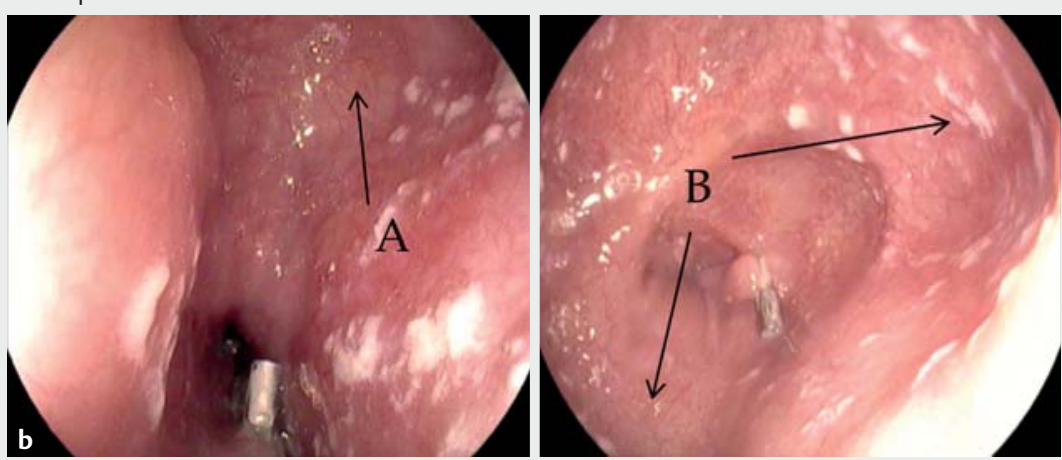

Fig. 1 Pre- (a) and postoperative (b) (1-month follow-up) gastroendoscopic images of two distinct esophageal diverticula: single esophageal diverticulum at $33 \mathrm{~cm}$ from the incisors (A); "kissing" esophageal diverticula at $43 \mathrm{~cm}$ from the incisors (B). 


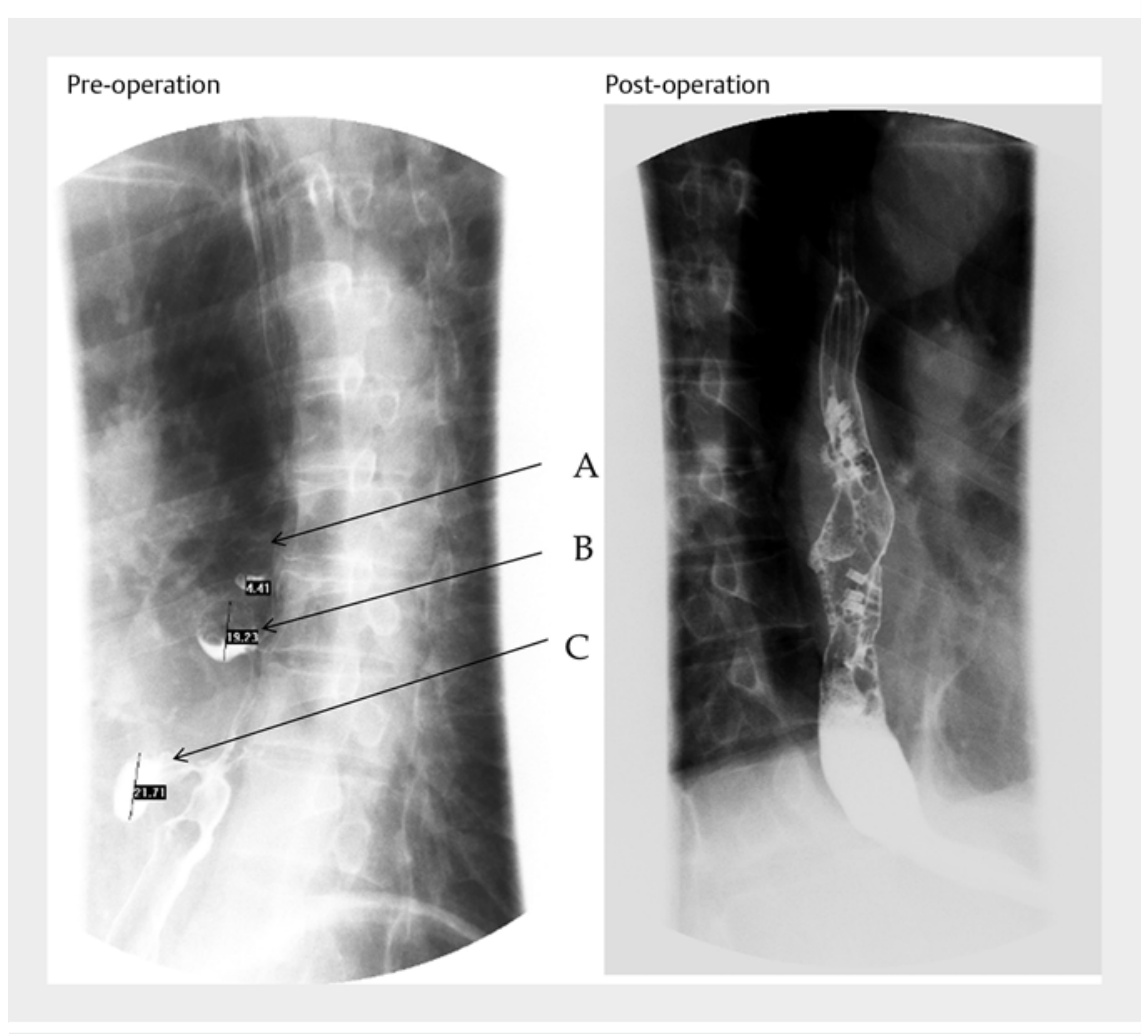

- Fig. 2 Pre- and postoperative (1-week follow-up) barium swallow results. The sizes of the three esophageal diverticula were $4 \mathrm{~mm}(\mathrm{~A}), 19 \mathrm{~mm}$ (B), and $22 \mathrm{~mm}$ (C), respectively.

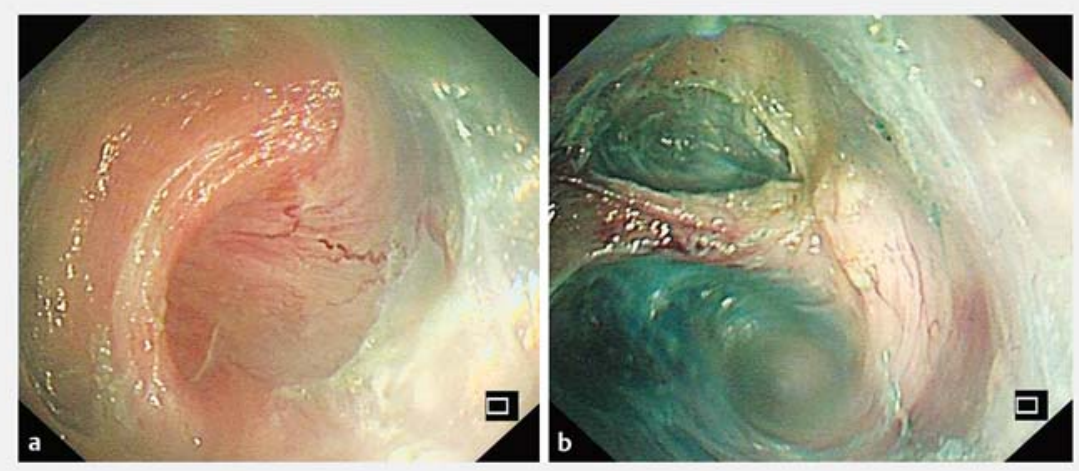

- Fig. 4 Peroral endoscopic myotomy of the single diverticulum. a A submucosal tunnel was made in the single esophageal diverticulum at $33 \mathrm{~cm}$ from the incisors. $\mathbf{b}$ The base muscle between the esophageal lumen and the diverticulum was dissected.

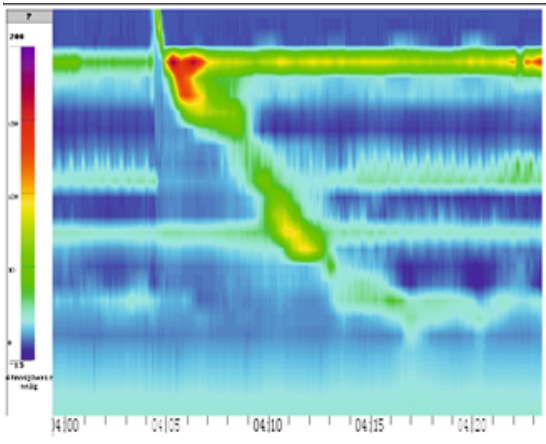

Fig. 3 Esophageal manometry results showed no findings of a primary motility disorder.

case, we successfully treated multiple esophageal diverticula by POEM, which expanded its application. Further studies on the long-term efficacy and follow-up after POEM are required.

Endoscopy_UCTN_Code_CCL_1AB_2AC_3AF

Competing interests

None

The authors

Li-Hua Ren, Ya-Dong Feng, Rui-Hua Shi Department of Gastroenterology, Zhongda Hospital, School of Medicine, Southeast University, Nanjing, China

\section{Corresponding author}

Rui-Hua Shi, PhD, MD

Department of Gastroenterology, Zhongda Hospital, School of Medicine, Southeast University, No. 87 Dingjiaqiao Road, Jiangsu Province, Nanjing 210009, China

Fax: +86-025-83262835

ruihuashi@126.com 


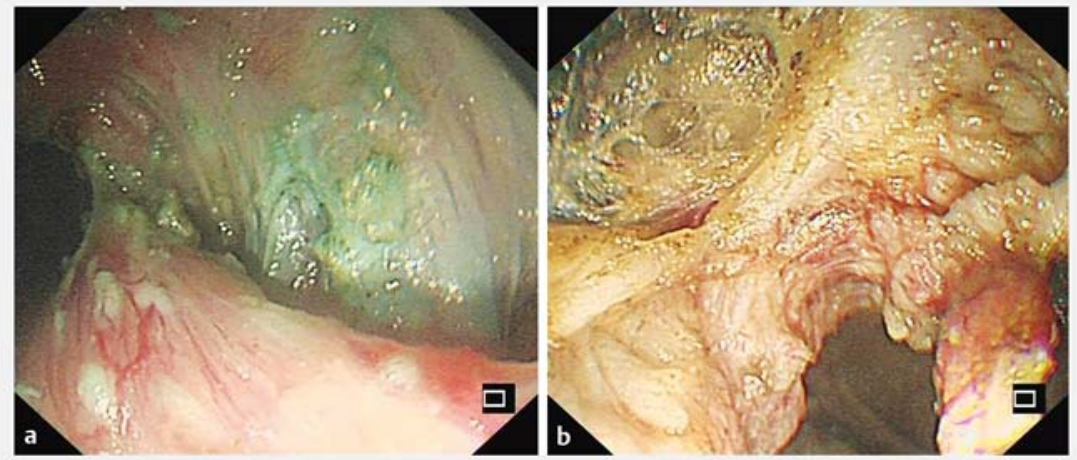

- Fig. 5 Peroral endoscopic myotomy of the "Kissing" esophageal diverticula. a A submucosal tunnel was made at $43 \mathrm{~cm}$ from the incisors. $\mathrm{b}$ The base muscle between the esophageal lumen and diverticula was dissected.

\section{References}

[1] Inoue H, Minami H, Kobayashi Y et al. Peroral endoscopic myotomy (POEM) for esophageal achalasia. Endoscopy 2010; 42: 265 271

[2] Li QL, Chen WF, Zhang XC et al. Submucosal tunneling endoscopic septum division: a novel technique for treating Zenker's diverticulum. Gastroenterology 2016; 151: $1071-1074$

[3] Wu C, Zhang Q, Liu W et al. Successful treatment of giant esophageal diverticulum by per-oral endoscopic myotomy. Endoscopy 2018; 50: E107-E108

\section{Bibliography}

DOI https://doi.org/10.1055/a-0836-2406

Published online: 13.3.2019

Endoscopy 2019; 51: E122-E124

(c) Georg Thieme Verlag KG

Stuttgart · New York

ISSN 0013-726X

\section{ENDOSCOPY E-VIDEOS}

https://eref.thieme.de/e-videos

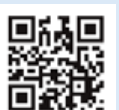

Endoscopy E-Videos is a free access online section, reporting on interesting cases and new

techniques in gastroenterological endoscopy. All papers include a high quality video and all contributions are freely accessible online.

This section has its own submission website at

https://mc.manuscriptcentral.com/e-videos 